\title{
Intrinsic caspase-8 activation mediates sensitization of erlotinib-resistant tumor cells to erlotinib/cell-cycle inhibitors combination treatment
}

\author{
M Orzáez ${ }^{\star, 1,3}, T_{\text {Guevara }}^{1,2,3}$, M Sancho ${ }^{1}$ and E Pérez-Payák, ${ }^{*, 2}$
}

Inhibitors of the tyrosine kinase activity of epidermal growth factor receptor, as erlotinib, have an established role in treating several cancer types. However, resistance to erlotinib, particularly in breast cancer cell lines, and erlotinib treatment-associated disorders have also been described. Also, methods and combination therapies that could reverse resistance and ameliorate nondesirable effects represent a clinical challenge. Here, we show that the ATP non-competitive CDK2/cyclin A inhibitor NBI1 sensitizes erlotinib-resistant tumor cells to the combination treatment (co-treatment) for apoptosis-mediated cell death. Furthermore, in erlotinib-sensitive cells, the effective dose of erlotinib was lower in the presence of NBI1. The analysis in the breast cancer MDA-MB-468 erlotinib-resistant and in lung cancer A549 cell lines of the molecular mechanism underlying the apoptosis induced by co-treatment highlighted that the accumulation of DNA defects and depletion of cIAP and XIAP activates the ripoptosome that ultimately activates caspases-8 and -10 and apoptosis. This finding could have significant implications for future treatment strategies in clinical settings.

Cell Death and Disease (2012) 3, e415; doi:10.1038/cddis.2012.155; published online 25 October 2012

Subject Category: Cancer

The protein kinase activity of the epidermal growth factor receptors (EGFRs) is of particular interest in the field of cancer. ${ }^{1-5}$ The deregulated proliferation of cancer cells is sustained by the production of growth factors in conjunction with the overexpression of growth factor receptors on the cell membrane. The EGFR family consists of four structurally related tyrosine kinase (TK) receptors (EGFR/ErbB-1, HER2/ ErbB-2, HER3/ErbB-3 and HER4/ErbB-4) located in the plasma membrane and activated in response to ligand binding. ${ }^{6}$ In physiological conditions, EGFRs are responsible for the regulation of proliferation, survival, migration and differentiation. ${ }^{7}$ Receptor dimerization induces cytoplasmic TK activity and initiates a cascade of events that produce survival, antiapoptotic or mitogenic signaling. Indeed, deregulation of this transduction pathway has a role in the process of malignant transformation, metastasis and resistance to apoptosis. ${ }^{8}$ A number of EGFR inhibitors have been developed, including monoclonal antibodies that target the ligandbinding extracellular domain of EGFR (e.g., cetuximab, panitumumab and trastuzumab) and low-molecular weight TK inhibitors that compete with adenosine triphosphate (ATP) to block the catalytic domain of the receptor (e.g., erlotinib, gefitinib, lapatinib and AG1478). ${ }^{9-11}$ These therapeutic agents have an established role in treating non-small cell lung, colorectal, pancreatic, breast and head and neck cancers, and erlotinib in particular has been approved by the FDA. ${ }^{9,12}$ However, resistance to erlotinib has also been described, particularly in breast cancer cell lines, ${ }^{13}$ and FDA alerts highlighted cases of hepatic failure, gastrointestinal perforation and ocular disorders ${ }^{14}$ as a result of erlotinib treatment. These non-desirable side effects may be ameliorated by decreasing the dosage used. Thus, an alternative might be to design combination therapies that can re-sensitize erlotinib-resistant cells and synergistically increase the therapeutic window of the drug, which would be aided by better understanding its molecular mechanism of action. ${ }^{15-18}$

The appearance of compensatory mechanisms favoring survival of cancer cells after therapy represents a limitation in therapies targeting specific molecules. Molecular pathways are interconnected, and thus, combination therapy is emerging as an appropriate strategy to treat certain types of cancer. Two of the strategies being explored are the blockade

\footnotetext{
${ }^{1}$ Laboratory of Peptide and Protein Chemistry, Centro de Investigación Príncipe Felipe, Valencia, Spain and ${ }^{2}$ Instituto de Biomedicina de Valencia, IBV-CSIC, Valencia, Spain

*Corresponding author: E Pérez-Payá or M Orzáez, Laboratory of Peptide and Protein Chemistry, Centro de Investigación Príncipe Felipe, Eduardo Primo Yúfera, 3 , Valencia E-46012, Spain. Tel: +34 963289680; Fax: +34 963289701; E-mail: eperez@cipf.es or morzaez@cipf.es

${ }^{3}$ These authors contributed equally to this work.

Keywords: cancer; cyclin-dependent kinases; EGFR; erlotinib; NBI1; ripoptosome

Abbreviations: A549, human alveolar basal epithelial adenocarcinoma cell line; AnnV, annexin V; ATP, adenosine triphosphate; CDK, cyclin-dependent kinase; Chk1, DNA damage effector checkpoint kinase 1; clAP1, cellular inhibitor of apoptosis protein 1; Cyt $c$, cytochrome $c$; EGFR, epidermal growth factor receptor; H2A.x, histone 2A.x; $\gamma$-H2Ax, gamma-histone 2A.x (phosphorylated on serine 139); IAP, inhibitor of apoptosis proteins; MDA-MB-468, human breast adenocarcinoma cell line; MCF-7, human breast adenocarcinoma cell line; MTT, 3-(4,5-dimethylthiazol-2-yl)-2,5-diphenyltetrazolium bromide; NBI1, all D-amino acid hexapeptide (D-Arg-D-Trp-D-lle-DMet-D-Tyr-D-Phe; rwimyf-NH $\mathrm{H}_{2}$ ATP non-competitive inhibitor of the kinase activity of the CDK2/cyclin A complex; PI, propidium iodide; RC, roscovitine; SKBr3, human breast adenocarcinoma cell line; TAT, a cell penetrating peptide (GRKKRRQRRRPQ) derived from the trans-activating transcriptional activator (Tat) from HIV-1; TAT-NBI1, a cell permeable derivative of the NBI1 peptide; TK, tyrosine kinase; XIAP, X chromosome-linked inhibitor of apoptosis protein

Received 04.7.12; revised 14.9.12; accepted 20.9.12; Edited by G Raschellá
} 
of related and proximal pathways. Accordingly, the dual inhibition of the vascular endothelial growth factor and EGFR pathways has been used to overcome the primary and acquired resistances, ${ }^{19}$ and combination therapies using inhibitors of the different members of the EGFRs are being explored to combat the activation of compensatory survival mechanisms within the same pathway. ${ }^{20}$ However, to effectively inhibit pathways proximal to the principal signaling pathways used, it is necessary to better understand the molecular mechanism involved in resistance.

EGFR inhibitors induce changes in the cell cycle, which can be considered to be proximal to the growth factor receptor pathway. Cell cycle controls the proliferation of eukaryotic cells and is controlled by a series of concerted mechanisms governed by members of the cyclin-dependent kinase family (CDKs). Increased CDK activity has been reported in cancer and CDKs have been proposed as targets in the search for anticancer drugs. Although several, ATP-competitive, synthetic inhibitors of CDKs are currently being developed, ${ }^{21}$ their selectivity remains unclear. The high degree of conservation of the catalytic domain of many protein kinases means ATP analogs and other ATP-competitive small molecule inhibitors often act on multiple protein kinases. Moreover, as cellular ATP levels are in the millimolar range, ATP-competitive inhibitors must bind with extremely high affinity to the ATPbinding site in order to be able to out-compete ATP. Indeed, we have early identified and characterized NBI1 and the cellpermeant derivative TAT-NBI1 as an all D-amino-acid hexapeptide, ATP non-competitive inhibitor of the kinase activity of the CDK/cyclin complexes. ${ }^{22}$

In sensitive cells, erlotinib inhibits cell growth by increasing the levels of the endogenous CDK inhibitor p2 $7^{K I P 1}$, suppressing CDK activity. ${ }^{15,23-25}$ Then, it was proposed that synthetic CDK inhibitors would sensitize erlotinib-resistant cells to the drug. Accordingly, the effects of ATP-competitive CDK inhibitors like flavopiridol and roscovitine $(R C)$ were analyzed in combination with EGFR inhibitors, ${ }^{26}$ although the molecular mechanisms involved were not described.

Here, we show that NBI1 sensitizes erlotinib-resistant tumor cells to the combination treatment for apoptosis-mediated cell death. Importantly, in both erlotinib-sensitive and erlotinibresistant cells, the effective dose of erlotinib was lower in the presence of TAT-NBI1. Among the key hallmarks of this process are the accumulation of damaged DNA in the cells and the depletion of cellular levels of inhibitor of apoptosis proteins (IAP) that induced the activation of caspase-8 and caspase-10. These two caspases were necessary for full apoptosis activation. siRNA-based silencing revealed that further activation of caspase-2 was caspase-10-dependent. Lastly, we provide novel evidence that TAT-NBI1/erlotinib co-treatment of erlotinib-resistant cells activates a death domain kinase RIP1-dependent apoptotic pathway that induces cell death.

\section{Results}

Treatment with NBI1 re-sensitizes cancer cell lines to erlotinib. Previous studies indicated that NBI1 and its cellpermeant derivative TAT-NBI1 inhibit a series of CDK/cyclin complexes, producing an anti-proliferative effect mediated by apoptosis in a number of different cancer cell lines. ${ }^{22} \mathrm{NBI} 1$ interacts in a conserved groove on the surface of some cyclins and has been proved to inhibit CDK2/cyclin A, CDK1/ cyclin B1, CDK6/cyclin D3 and CDK7/cyclin H with IC50s in the low micromolar range, whereas the IC50s for the transcriptional CDK9/cyclin T1 was found $>50 \mu \mathrm{M}$ (Supplementary Table S1). TAT-NBI1 is able to induce cell death in a broad panel of cancer cell lines (Supplementary Figure S1 and Table S2). We have also synthesized a fluorescent derivative of TAT-NBI1 (CF-TAT-NBI1) and demonstrated that the drug was internalized by the cell, reached the nucleus (Supplementary Figure $\mathrm{S} 1 \mathrm{~A}$ ) and induced cell death by intrinsic, mitochondrial-mediated, apoptosis as followed by cytochrome $c$ (Cyt $c$ ) release to the cytosol (Supplementary Figure S1B).

It is reasonable to postulate that drug-induced restoration of CDK inhibition even at sub-lethal NBI1 doses may contribute to the re-sensitization of resistant cells to EGFR inhibitors, thereby lowering the effective dose of erlotinib. To test this hypothesis, we selected three breast cancer cell lines (MCF-7, SKBr3 and MDA-MB-468) and a non-small cell lung cancer cell line (A549). These cell lines exhibited a concentrationdependent sensitivity to erlotinib (Figure 1a). Concentrations of erlotinib $>20 \mu \mathrm{M}$ could not be achieved due to the low solubility of this compound in culture medium. Nevertheless, as the plasma concentration in patients with advance solid tumors is $\sim 5 \mu \mathrm{M}$ at the steady state, ${ }^{27} \mathrm{SKBr} 3$ was considered as erlotinib-sensitive cell line, whereas the MCF-7, MDA-MB-468 and A549 cell lines were considered erlotinib-resistant (Figure 1a), in accordance with previously reported data. ${ }^{23}$

In the present study, we first evaluated the anti-proliferative activity of TAT-NBI1 in the above-mentioned cell lines to determine the IC50 values (Figure 1a) and the threshold to define sublethal concentrations (Supplementary Table S3). Similar experiments were performed with RC (an ATPcompetitive inhibitor of CDK/cyclin complexes) and erlotinib.

Combination treatments (co-treatments) with TAT-NBI1/ erlotinib and RC/erlotinib were carried out at sublethal concentrations of each drug and at $72 \mathrm{~h}$ of exposure cell viability was determined by 3-(4,5-dimethylthiazol-2-yl)-2, 5-diphenyltetrazolium bromide (MTT) and trypan blue exclusion assays (Figure 1). A complementary, more detailed kinetic analysis at different exposure times was performed for MDA-MB-468 and A-549 cell lines (Supplementary Figures S2A, B and S3A). In the MDA-MB-468 cell line, at $72 \mathrm{~h}$ of exposure, the co-treatments induced the death of almost $75 \%$ of cells (Figures $1 \mathrm{~b}$ and $\mathrm{c}$ ). Similar effects were observed in the A549 (Figures $1 \mathrm{f}$ and g) and MCF-7 (Figures $1 \mathrm{~h}$ and i) cell lines. Interestingly, TAT-NBI1/erlotinib co-treatment decreased the lethal concentration (compound concentration needed to induce $50 \%$ of cell death) of erlotinib from 5 to $2 \mu \mathrm{M}$ in the SKBr3 erlotinib-sensitive cell line in function of the TAT-NBI1 dose (Figures $1 \mathrm{~d}$ and e). These results suggested that a coadministration of a CDK2/cyclin A inhibitor with erlotinib resensitizes resistant cells to erlotinib, and it also reduces the lethal dose in erlotinib-sensitive cells, thereby widening the therapeutic window of the drug while diminishing the possible side effects. The drug combination indices of all the drug combinations administered were $<1$, indicating a synergistic drug behavior. ${ }^{26}$ 


\begin{tabular}{|c|c|c|c|c|c|}
\hline Cell line & HER2 & EGFR & ER & $\begin{array}{c}\text { Erlotinib } \\
\text { IC50 }(\boldsymbol{\mu} \mathbf{M})\end{array}$ & $\begin{array}{c}\text { NBI1 } \\
\text { IC50 }(\boldsymbol{\mu} \mathbf{M})\end{array}$ \\
\hline MDA-MB-468 & $\mathrm{n}$ & $\mathrm{p}$ & $\mathrm{n}$ & $>20$ & 15 \\
\hline SKBr3 & $\mathrm{p}$ & $\mathrm{n}$ & $\mathrm{n}$ & 5 & 10 \\
\hline A549 & $\mathrm{p}$ & $\mathrm{p}$ & $\mathrm{n}$ & $>20$ & 18 \\
\hline MCF-7 & $\mathrm{n}$ & $\mathrm{n}$ & $\mathrm{p}$ & $>20$ & 11 \\
\hline
\end{tabular}

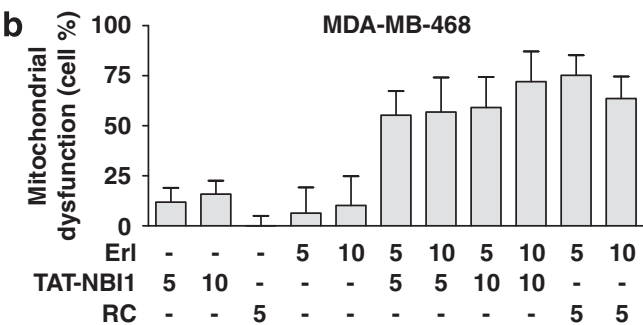

d

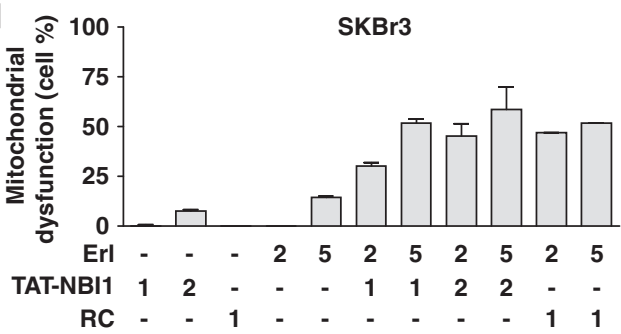

f $\odot 100] \quad$ A549

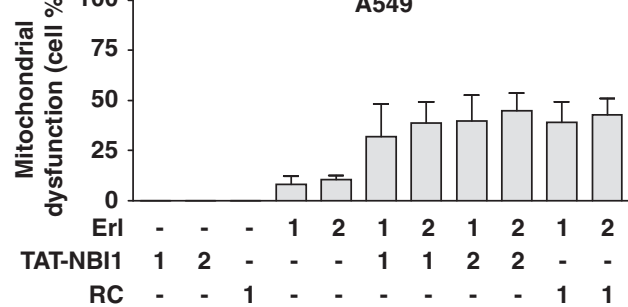

h

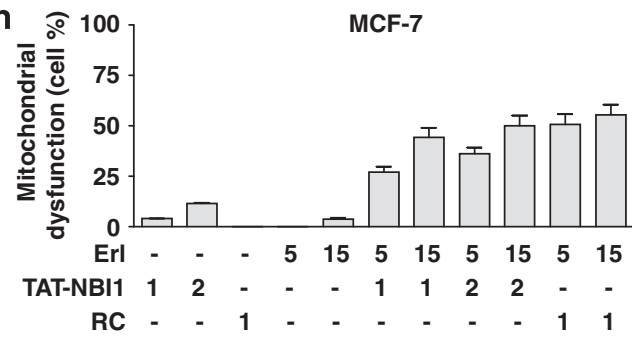

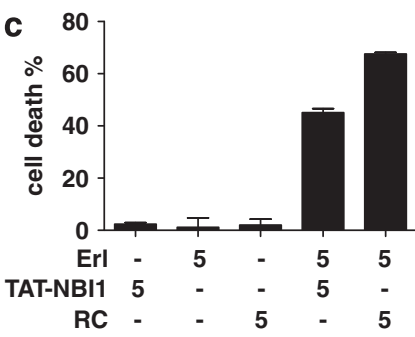
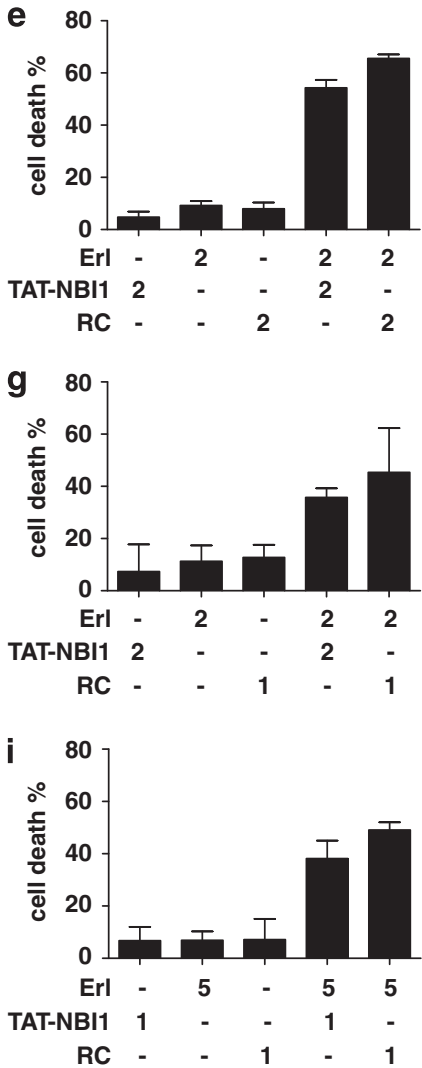

Figure 1 TAT-NBI1/erlotinib and roscovitine/erlotinib combination treatments induce cell death. (a) Classification of cell lines as positive (p) or negative (n) for the expression of the HER2, EGFR and ER receptors. IC50 values of the different cell lines for the treatment with TAT-NBI1 or erlotinib. Cells were treated with sublethal concentrations of erlotinib (Erl), TAT-NBI1 and roscovitine (RC), or combinations of these drugs. The doses are expressed in $\mu \mathrm{M}$ in the $\mathrm{x}$ axes. At $72 \mathrm{~h}$, cell viability was assessed with MTT and trypan blue exclusion assay. The behavior of the erlotinib-resistant cells MDA-MB-468, A549 and MCF-7 is plotted in panels (b, $\mathbf{f}, \mathbf{h})$ and (c, $\mathbf{g}, \mathbf{i})$ for MTT and trypan blue, respectively, while the erlotinib sensitive SKBr3 cells is plotted in panels (d and e). The data are expressed as the mean \pm S.E. ( $n>3$ )

The effect of TAT-NBI1/erlotinib co-treatment on cellcycle progression. To initially characterize the in cellulo mechanism of action of TAT-NBI1/erlotinib co-treatment, we analyzed the cell-cycle distribution in the cultures at different time points $(24,48$ and $72 \mathrm{~h})$. In the MDA-MB-468, SKBr3 and A549 cell lines (Figures $2 \mathrm{a}-\mathrm{c}$, respectively), cotreatment significantly decreased the proportion of cells in the $\mathrm{G} 1$ and $\mathrm{G} 2 / \mathrm{M}$ phases after $48 \mathrm{~h}$, resulting in an increase in the proportion of subG1 cells after 48 and $72 \mathrm{~h}$ of co-treatment. The proportion of cells accumulated in subG1, close to $50 \%$ in all the three cell lines, was comparable to the decrease in cell viability observed (Figure 1), suggesting apoptosis as the main mechanism of cell death. By contrast, the MCF-7 cell line did not show subG1 population after a $72 \mathrm{~h}$ co-treatment (Figure 2d).

Understanding the mechanism of cell death induced by TAT-NBI1/erlotinib co-treatment. To further explore the 
a
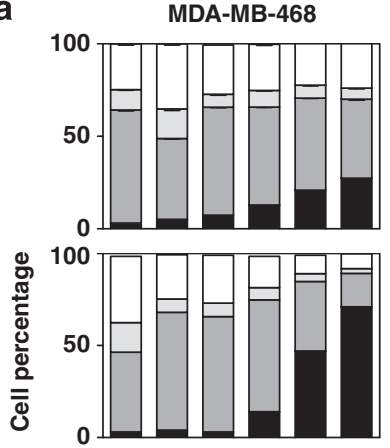

$\left.\left.\left.\left.\left.1000^{-}\right|^{-}\right|^{-}\right|^{-}\right|^{-}\right|^{-}$

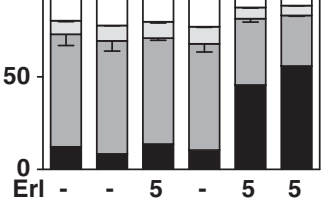

TAT-NBI1 - $5-5-5 \quad-$

$\mathrm{RC}-\quad-5-5$

-SubG1 $\square \mathrm{G} 1 \square \mathrm{S} \square \mathrm{G} 2 / \mathrm{M}$
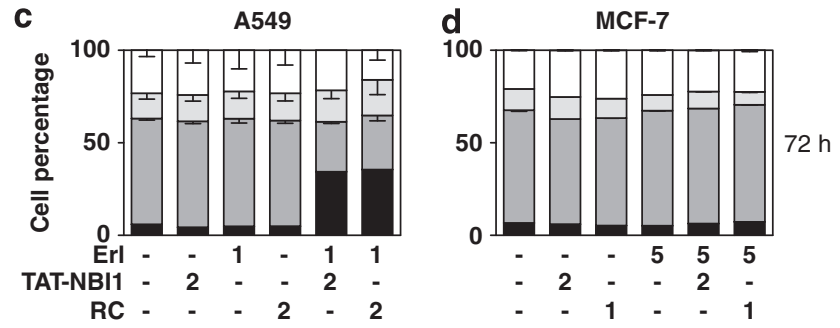

口 SubG1 $\square$ G1 $\square$ S $\square$ G2/M

Figure 2 TAT-NBI1/erlotinib and roscovitine/erlotinib combination treatments induce subG1 accumulation in different cell lines. The cell-cycle distribution was analyzed by flow cytometry following treatment for the periods indicated with sublethal concentrations of erlotinib (Erl), TAT-NBI1, roscovitine (RC) and combinations thereof. The doses are expressed in $\mu \mathrm{M}$ in the $\mathrm{x}$ axes. The results obtained after 24,48 and $72 \mathrm{~h}$ of treatment are plotted in panels (a) and (b) for MDA-MB-468 and SKBr3 cells, respectively. The cell-cycle distribution of (c) A549 and (d) MCF-7 cells after $72 \mathrm{~h}$ of treatment is plotted. The data are expressed as the mean \pm S.E. $(n=3)$

mechanism of TAT-NBI1/erlotinib-induced cytotoxicity, we analyzed different markers of apoptosis and necrosis. The exposure of phosphatidylserine residues on the outer leaflet of the plasma membrane is usually considered a hallmark of apoptosis. ${ }^{28}$ Thus, cell staining with fluoresceinisothiocyanate-labeled Annexin V, which binds to phosphatidylserine, is considered to be a marker of early apoptotic events $\left(\mathrm{AnnV}^{+}\right)$. Propidium iodide $(\mathrm{PI})$ is a DNA intercalating agent that can be incorporated into cells only after major cell membrane damages $\left(\mathrm{PI}^{+}\right)$. Hence, the combination of AnnV and $\mathrm{PI}$ cell staining can be used to distinguish apoptotic and necrotic cell death. Co-treatment of MDA-MB-468 and SKBr3 cell lines produced the typical profile of cells undergoing apoptosis after $48 \mathrm{~h}$, as both $\mathrm{AnnV}^{+} \mathrm{Pl}^{-}$(early apoptotic) and $\mathrm{AnnV}^{+} \mathrm{PI}^{+}$(late apoptotic) cells could be detected (Figures $3 a$ and b). Co-treatment of the A549 cell line resulted in the death of $\sim 35 \%$ of cells (Figure 3c). By contrast, following the same co-treatment, the main population of dying MCF-7 cells was AnnV ${ }^{-} \mathrm{PI}^{+}$suggestive of cell
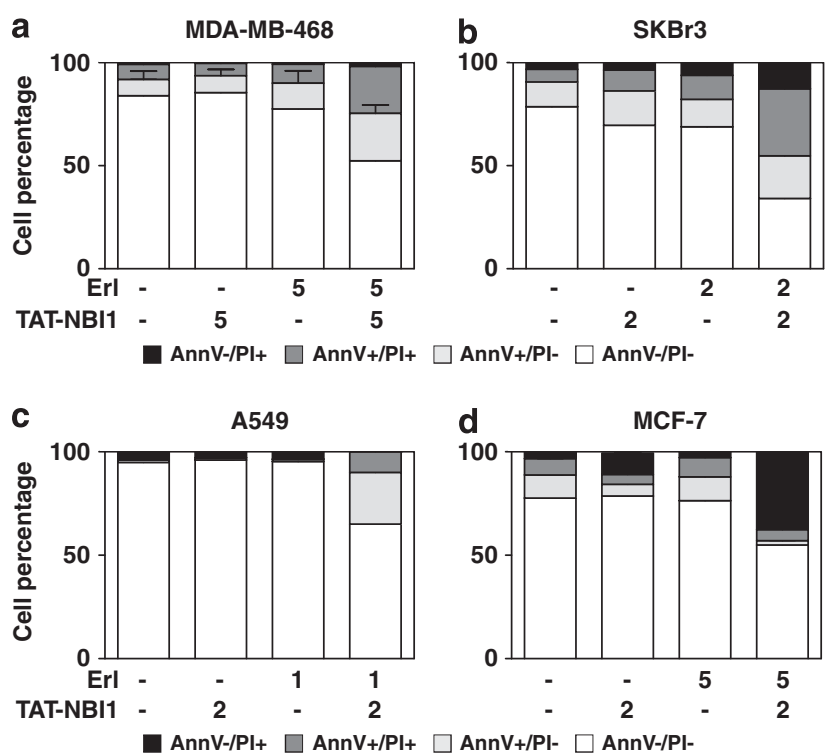

Figure 3 The cell-death mechanism induced by TAT-NBI1/erlotinib cotreatment differs between the different cell lines analyzed. Cells were treated with the indicated concentrations $(\mu \mathrm{M})$ of erlotinib (Erl), TAT-NBI1 or the combination of both. After $72 \mathrm{~h}$ of treatment, apoptotic parameters were analyzed in cells by cytofluorometry. Quantitative data for AnnexinV/propidium iodide (AnnV/PI) staining of (a) MDA-MB-468, (b) SKBr3, (c) A549 and (d) MCF-7 cells are shown. The data are expressed as the mean \pm S.E. $(n=3)$

necrosis (Figure 3d). This latter finding was expected as the MCF-7 cell line is deficient in caspase- 3 , and thus, apoptotic cell death is compromised. ${ }^{29}$ Taken together, these findings suggest that the co-treatment of different tumor cells with TAT-NBI1 and erlotinib induces distinct cell-death programs depending on the genetic background.

Nevertheless, the molecular mechanism that mediates cellcycle inhibition by CDK inhibitors, inhibition of the EGFR pathway and induction of apoptosis remains unclear. We selected the MDA-MB-468 cell line to further study the molecular mechanism underlying these events. A feature of this cell line is an allelic loss of the BRAC1 (breast cancer 1) gene, which in turn is associated with a poor therapeutic prognosis. This gene is part of a genome surveillance complex that senses abnormal DNA structures, such as double-strand breaks and base pair mismatches. ${ }^{30}$ As CDK2 is thought to have an important role in the DNA repair machinery, ${ }^{31}$ we therefore reasoned that the re-sensitization of the MDA-MB-468 cell line to erlotinib, that was induced by $\mathrm{CDK} 2 /$ cyclin A inhibition, may be related to the irreversible accumulation of non-repaired DNA damage, which in turn initiates the apoptotic program. DNA damage induces the phosphorylation of histone 2A.x (H2A.x) at Ser139 by PI3-Klike kinases, including ATM, ATR and DNA-PKc. ${ }^{32,33}$ In addition, the DNA damage effector checkpoint kinase 1 (Chk1) is activated by ATR-dependent phosphorylation to transduce damage signals to downstream effectors that control DNA repair and apoptosis. ${ }^{34}$ Reduced phosphorylation of Chk1 would dampen its activity and abrogate DNA damage-induced repair mechanisms, favoring cell apoptosis. We monitored the Ser139 phosphorylation of H2A.x $(\gamma-H 2 A . x)$ 
a
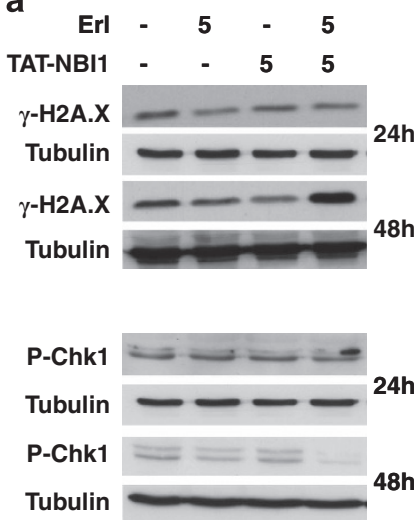

b
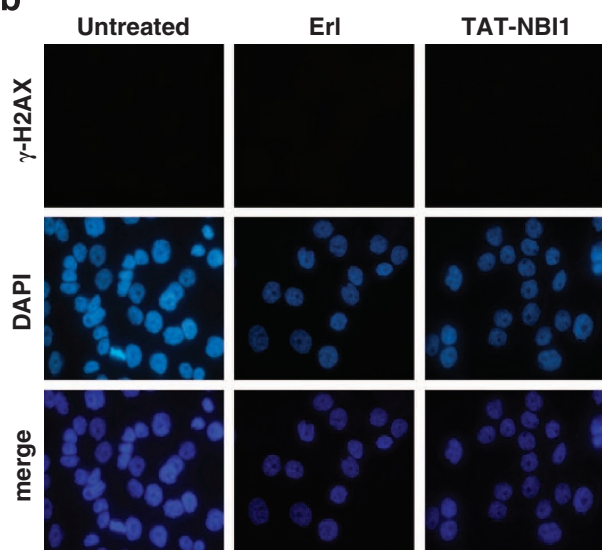

Erl TAT-NBI 1
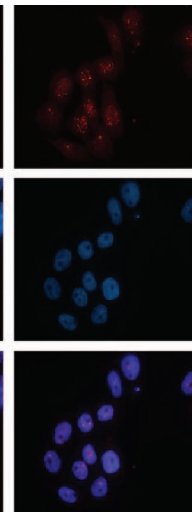

Figure 4 Damaged DNA accumulates in MDA-MB-468 cells co-treated with TAT-NBI1/erlotinib. Cells were treated with of TAT-NBI1 $(5 \mu \mathrm{M})$, erlotinib (Erl; $5 \mu \mathrm{M})$ or a combination of both. (a) Analysis of the phosphorylation levels of H2A.x and Chk1 detected by western blotting. Phosphorylation of H2A.x at Ser 139 ( $\gamma$-H2A.x; upper panels) and Ser 317 phosphorylated Chk1 (P-Chk1; lower panels) were analyzed at 24 and $48 \mathrm{~h}$. Fold increase after $48 \mathrm{~h}$ of treatment was analyzed by densitometry (right panels). The data are expressed as the mean \pm S.E. $(n=3)$. $(\mathbf{b})$ Phosphorylation of H2A.x was also analyzed by immunofluorescence (red) after $48 \mathrm{~h}$ of treatment. Cell nuclei were stained with DAPI (blue)

and the Ser317 phosphorylation of Chk1 (P-Chk1) (Figure 4). TAT-NBI1/erlotinib co-treatment significantly increased at $48 \mathrm{~h}$ the level of $\gamma$-H2A.x (Figures $4 a$ and b), whereas decreasing that of P-Chk1 (Figure 4a) in comparison to that detected following treatment with either compound alone. Together, these findings indicate that TAT-NBI1/erlotinib cotreatment that induces the accumulation of DNA defects (reflected by the increase of $\gamma-\mathrm{H} 2 \mathrm{~A} . \mathrm{x}$-Figures $4 \mathrm{a}$ and $\mathrm{b}$ ) might be due to the repression of DNA repair programs (decreased levels of P-Chk1-Figure 4a) inducing apoptosis.

Analysis of the cell-death pathway induced by TATNBI1/erlotinib co-treatment in erlotinib-resistant MDAMB-468 cells. The apoptotic pathway is under the control of proteins of the Bcl-2 family and of the IAPs. ${ }^{35-37}$ In particular, cellular IAP1 (cIAP1) and human X chromosome-encoded IAP (XIAP) are both implicated in regulation of apoptosis. ${ }^{38}$
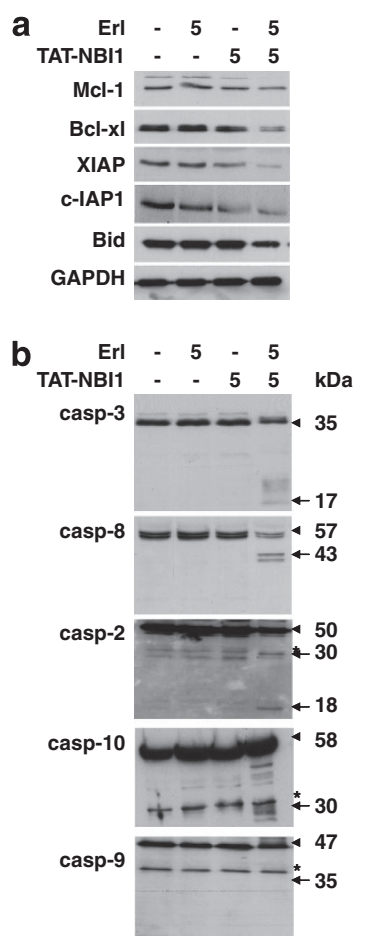

C

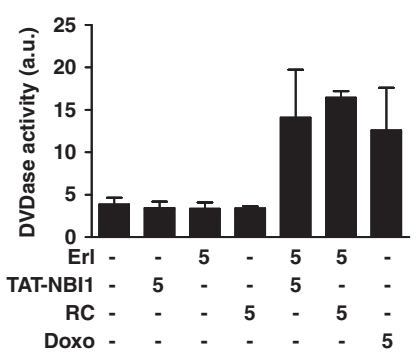

d

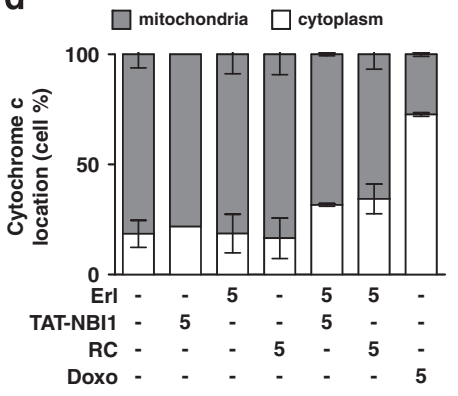

Figure 5 Quantification of apoptosis-related parameters in MDA-MB-468 cells after co-treatment with TAT-NBI1/erlotinib. Cells were treated for $72 \mathrm{~h}$ with TAT-NBI1, erlotinib (Erl) or a combination of both at the concentrations indicated $(\mu \mathrm{M})$. (a) The expression of the anti-apoptotic Bcl-2 proteins Mcl-1 and Bcl-xl, the inhibitor of apoptosis proteins XIAP and CIAP1 and the BH3-only Bid protein was analyzed in western blots of total cell extracts. In panel (b), the cellular extracts were analyzed by western blotting for the expression of the executioner caspase-3 (procaspase-3, $35 \mathrm{kDa}$; processed caspase-3, $17 \mathrm{kDa}$ ); the initiator caspase-8 (procaspase-8, $57 \mathrm{kDa}$; processed caspase-8, $43 \mathrm{kDa}$ ); the initiator caspase-2 (procaspase-2, $50 \mathrm{kDa}$; processed caspase-2, 30 and $18 \mathrm{kDa}$ ); the initiator caspase-10 (procaspase-10, $58 \mathrm{kDa}$; processed caspase-10, $30 \mathrm{kDa}$ ) and the initiator caspase-9 (procaspase-9, $47 \mathrm{kDa}$; processed caspase-9, 37/35 kDa not detected). Asterisk marks for unspecific bands recognized by the antibody. (c) TAT-NBI1/ erlotinib co-treatment $(\mu \mathrm{M})$ induced a similar level of caspase activity to that observed when cells were treated with doxorubicin (doxo) at $5 \mu \mathrm{M}$. (d) Doxo $(5 \mu \mathrm{M})$ induced intrinsic (mitochondrial-mediated) apoptosis in MDA MB-468 cells, as determined by cytofluorometric determination of Cyt $c$ released into the cytoplasm (white bars). TAT-NBI1/erlotinib co-treatment only induced basal levels of Cyt $c$ release

To investigate the role of $\mathrm{Bcl}-2$ family members and IAPs in the apoptosis induced by TAT-NBI1/erlotinib co-treatment, we analyzed the expression of $\mathrm{Mcl}-1, \mathrm{Bcl}-\mathrm{xL}$, XIAP, ClAP1, Bid, Bax and Bim, when compared with single drug treatments (Figure 5 and Supplementary Figure S2E). Cotreatment downregulated the expression of $\mathrm{Mcl}-1$ and $\mathrm{Bcl}-\mathrm{xL}$ (Figure 5a), as well as triggering XIAP and cIAP1 depletion (Figure 5a), whereas it had no effect on the pro-apoptotic Bax protein (Supplementary Figure S2E).

Two distinct cell-death mechanisms have been linked to CIAP1 and XIAP depletion, one related to the tumor necrosis factor-mediated activation of complex-III ${ }^{39,40}$ and the second involving the 'genotoxic stress'-mediated assembly of a recently described complex known as the 'ripoptosome'. ${ }^{41,42}$ When we analyzed the pathways by which TAT-NBI1/erlotinib co-treatment induced cell death, caspase-8 was found 

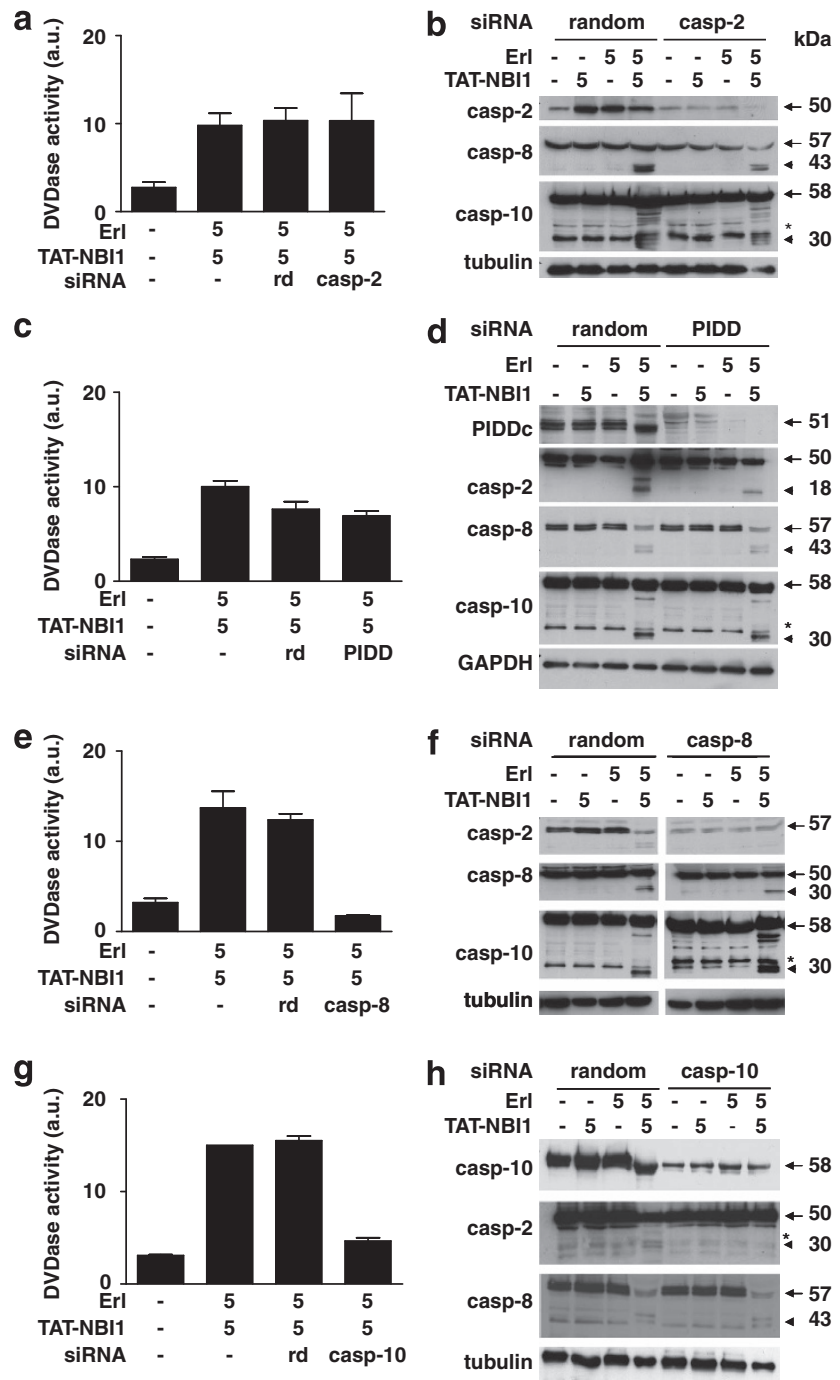

Figure 6 Caspases-8 and -10, but not caspase-2, are required to engage the TAT-NBI1/erlotinib co-treatment-induced apoptotic program. (a) MDA-MB-468 cells were untreated or transfected with a control (random) or a caspase-2 specific (casp-2) si-RNA. Silencing of caspase-2 (see Materials and Methods) does not affect NBI1/ erlotinib (at the $\mu \mathrm{M}$ concentrations indicated) co-treatment-induced caspase-3/7 activation evaluated at $48 \mathrm{~h}$ post-treatment. (b) Cellular extracts of MDA-MB-468 cells treated as in $\mathbf{a}$, were analyzed by western blot for the expression of caspase-2 to corroborate the silencing as well as for the activation of caspases-8 and -10 . Similar procedures were used for the analyses of the silencing of PIDD (c and $\mathbf{d}$ ) and for caspase-8 (e and $\mathbf{f}$ ) and caspase-10 ( $\mathbf{g}$ and $\mathbf{~}$; see Materials and Methods) that inhibited NBI1/erlotinib co-treatment induced caspase-3/7 activity

activated and processed to its active form (Figure 5b), which in turn cleaved the $\mathrm{BH} 3-$ only protein $\mathrm{Bid}$, as revealed by a decrease in the full-length Bid (Figure 5a). In addition, these events induced the processing of executioner caspase- 3 to its active $\mathrm{p} 20$ and $\mathrm{p} 17$ subunits (Figure $5 \mathrm{~b}$ ). The $\mathrm{BH} 3$-only protein Bim has been implicated in erlotinib-induced apoptosis, ${ }^{43}$ and we found that Bim was upregulated in response to both erlotinib alone and TAT-NBI1/erlotinib co-treatment (Supplementary Figure S2E). However, while the latter induced the accumulation of DNA defects and cell death, erlotinib alone did not provoke cell death in these erlotinib-resistant cells (Figures 1 and 3 ). We next investigated the effect of co-treatment on the initiator caspases -2, -9 and -10 . Caspases -2 and -10 were processed to their active subunits following co-treatment, whereas caspase-9 processing was not detected (Figure $5 b$ ). There was a similar level of caspase activity induced by co-treatment to that induced by the apoptosis-inducer doxorubicin (Figure 5c). However, while doxorubicin-induced apoptosis occurred via the mitochondrial-mediated intrinsic pathway characterized by Cyt $c$ release to the cytoplasm, the liberation of Cyt $c$ induced by TAT-NBI1/erlotinib co-treatment was minimal (Figure $5 \mathrm{~d}$ ). These results suggest that TAT-NBI1/erlotinib-induced DNA damage induces apoptosis through the activation of caspases-2, -8 and -10 , independent of the mitochondrial pathway. We next investigated the role of caspase-2 and the initiator caspases-8 and -10 in TAT-NBI1/erlotinib-induced apoptosis. We tested the effect of caspase-2, -8 and -10 loss on the apoptotic response, as determined by the NBI1/ erlotinib-induced activation of caspase activity in cellular extracts. The caspase activity (Figure 6a) induced by co-treatment was not affected by silencing caspase-2 expression and caspases- 8 and -10 were processed to their active subunits (Figure 6b). Knockdown of PIDD also failed to suppress TAT-NBI1/erlotinib-induced cell death, excluding the involvement of the PIDDosome as the complex in charge of apoptosis activation (Figures $6 \mathrm{c}$ and d). However, we noted a marked decrease in caspase activity and cell viability when caspase-8 (Figure 6e and Supplementary Figure S2D) and caspase-10 (Figure 6g) were silenced individually. Silencing caspase-10 prevented processing of caspase-2, whereas caspase-8 was processed to its active subunits (Figure 6h), and silencing of caspase-8 did not prevent the processing of caspases-10 and -2 (Figure 6f). The activation of both caspases- 8 and -10 is needed for full general activation of caspases as demonstrated in Figures $6 \mathrm{e}$ and $\mathrm{g}$. These results suggest that in MDA-MB-468 cells, the TAT-NBI1/erlotinib cotreatment induces caspase- 2 activation mediated by caspase-10 (Figure 6h) but caspase-2 has not a direct implication in apoptosis induction (Figure 6a). Similar results have been previously reported on the still enigmatic activation of caspase-2 that resulted in cell death in particular cell types, while in other cells leads to growth suppression coupled to sensitization to apoptosis. ${ }^{44}$ Furthermore, we obtain the same relevant role for caspase- 8 in cell sensitazion when the analysis of the molecular mechanism was performed in the lung cancer A549 cell line (Supplementary Figure S3).

Despite caspases activation, we found that TAT-NBI1/ erlotinib-dependent cell-death induction was not inhibited by the caspase inhibitor zVAD-fmk (Z-Val-Ala-Asp(OMe)-fluoromethylketone; Supplementary Figure S2C). However, cell death induced by RC/erlotinib was inhibited by zVAD-fmk. The molecular basis of these differences could be justified by the different mechanism of action of the two different CDK/ cyclin inhibitors. Therefore, the kinase selectivity and the sensitivity of the different CDK/cyclin complexes are different for the two drugs (Supplementary Table S1 and Bach et al. ${ }^{45}$ ). Hence, such differences could determine the differential response in the presence of ZVAD-fmk.

It has been recently reported that 'ripoptosome'-mediated cell death is not inhibited by zVAD-fmk due to the 

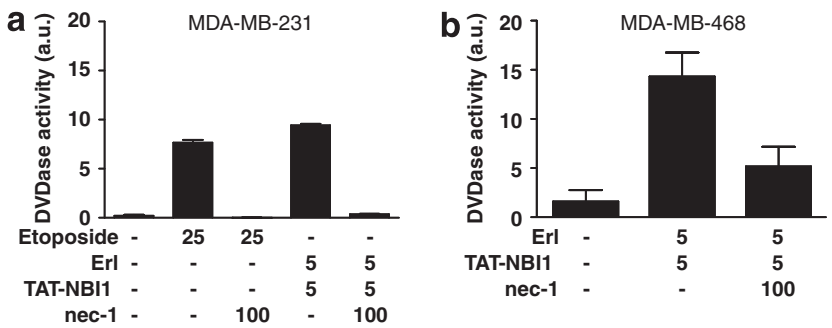

Figure 7 Engagement of co-treatment-induced apoptotic program depends on the ripoptosome. (a) Etoposide $(25 \mu \mathrm{M})$ induced activation of caspase-3/7 in MDA-MB-231 cells was inhibited in the presence of nec-1 $(100 \mu \mathrm{M})$. Similarly, the caspase-3/7 activation induced by the NBI1/erlotinib co-treatment (at the $\mu \mathrm{M}$ concentrations indicated) in these cells was inhibited by nec-1. (b) The NBI1/ erlotinib (at the $\mu \mathrm{M}$ concentrations indicated) co-treatment-induced caspase-3/7 activation in MDA-MB-468 cells was inhibited by nec- 1 .

ripoptosome's ability to switch between apoptosis and necroptosis. ${ }^{41,42}$ The 'ripoptosome' is a cell-death-inducing platform containing the death domain kinase RIP1, the Fasassociated death domain protein, caspase- 8 and caspase- 10 that assembles in response to loss of clAPs and XIAP.41,42 We next evaluated the influence of the 'ripoptosome' in TATNBI1/erlotinib-induced apoptosis. To this end, we use the RIP1 inhibitor necrostatin-1 (nec-1). ${ }^{46}$ We initially explored the role of nec-1 as inhibitor of the 'ripoptosome' in a cell line (MDA-MB-231—experimentally determined IC50 values for this cell line: $>20$ and $18 \mu \mathrm{M}$ for erlotinib and TAT-NBI1, respectively) where such platform was previously characterized. ${ }^{42}$ This cell line respond to etoposide-induced genotoxic stress through 'ripoptosome'-mediated and caspase-dependent cell death, which is inhibited by nec-1 (Figure 7a). Interestingly, nec-1 also inhibited TAT-NBI1/erlotinib-induced caspase activation in both MDA-MB-231 and MDA-MB-468 cells (Figures $7 a$ and $b$, respectively). These results suggest that the 'ripoptosome' could have a role in the cell death induced by TAT-NBI1/erlotinib co-treatment.

\section{Discussion}

Recent findings have demonstrated that cancers respond to therapies targeting receptor TKs. However, the benefits of this approach are limited by the development of resistances and the toxic secondary effects induced by high doses of TK inhibitors, prompting the search for possible alternatives. Combination therapies have attracted considerable attention as tools to effectively circumvent the toxicity and resistance seen with single-agent therapies, even though the underlying molecular mechanisms remain unclear and the most appropriate compounds with which to prime the cell to promote a synergistic effect remain poorly understood. ${ }^{47} \mathrm{~A}$ better understanding of the synergism and/or potentiation evoked at the molecular level by drug combinations will aid the development of improved combinations and personalized treatments in the future.

Here, we show that co-administration of TAT-NBI1, an ATP non-competitive inhibitor of the CDK2/cyclin A complex, with erlotinib, an inhibitor of the TK activity of the EGFR, decreases the lethal dose of erlotinib in erlotinib-sensitive cells and sensitizes erlotinib-resistant cells to the cell death provoked by this drug. TAT-NBI1/erlotinib co-treatment induced necrosis in erlotinib-resistant MCF-7 (human breast adenocarcinoma) cell line that carries different mutations favoring necrotic cell death over apoptosis. ${ }^{29}$ By contrast, in the erlotinib-sensitive SKBr3 (human breast adenocarcinoma) cell line and the erlotinib-resistant MDA-MB-468 (human breast adenocarcinoma) and A549 (human alveolar basal epithelial adenocarcinoma) cell lines, TAT-NBI1/erlotinib cotreatment induced apoptosis. Remarkably, the lethal dose of erlotinib in SKBr3 cells was twofold lower in the presence of TAT-NBI1. This sensitization of both erlotinib-sensitive and erlotinib-resistant cancer cells demonstrated an important enhancement in the therapeutic value of EGFR inhibitors when administrated in combination with ATP non-competitive CDK-2/cyclin A inhibitors, such as TAT-NBI1. We investigated the molecular mechanism in MDA-MB- 468 and A549 cells and found that TAT-NBI1/erlotinib co-treatment induced genotoxic stress as manifested by the accumulation of DNA defects in treated cells. Indeed, we observed depletion of IAPs and alterations in the levels of apoptosis-related proteins such as $\mathrm{Bcl}-\mathrm{xL}, \mathrm{Mcl}-1$, Bid and Bim together with the activation of the apoptotic signaling pathway that ultimately activates caspases. Our data suggest that the TAT-NBI1/erlotinib-induced genotoxic stress could induce the activation of the 'ripoptosome, ${ }^{41,42}$ as the molecular machinery driving the activation of the initiator caspases-8 and -10 . We found that, despite the reduction of antiapoptotic $\mathrm{Bcl}-2$ protein levels that could sensitize cells for death programs, TAT-NBI1/erlotinibinduced caspase-dependent cell death occurred without activation of the intrinsic apoptotic pathway, as witnessed by the low levels of Cyt $c$ release and the absence of caspase- 9 activation. In the presence of the RIP1 inhibitor nec-1, TATNBI1/erlotinib-induced cell death was drastically impaired. Moreover, the RNA-mediated silencing of caspase-8, or caspase-10 but not caspase-2, decreased the TAT-NBI1/ erlotinib-induced activation of effector caspases, implicating a signaling pathway in which caspase-2 is positioned downstream of caspase-8/10 (Figure 7c). Interestingly, it has been recently reported that a time-staggered treatment with erlotinib sensitizes a subset of breast cancer cells to a DNA damaging agent as doxorubicin and the process is mediated by caspase- 8 activation. ${ }^{47}$ The molecular mechanism in charge of caspase-8 activation has not been reported although it is tempting to speculate that it could be related to the one described in the present study.

\section{Materials and Methods}

Antibodies, chemicals and cell lines. Antibodies for Bax (No.2772), Bcl-xL (No.2764), Bid (No.2002), Bim (No.2819), caspase-3 (No.9662), caspase-8 (No.9748), caspase-9 (No.9508), phospho-Chk1 (No.23425), GAPDH (No.2018), $\gamma$-H2Ax (Ser 139; No.9718S), cIAP1 (No.4952), Mcl-1 (No.4572) and XIAP (No.2042) were from Cell Signaling (Danvers, MA, USA). PIDD antibody (ALX-804-837) was from Enzo Life Sciences (Farmingdale, NY, USA). Caspase-10 antibody (M059-3) was purchased from MBL (Woburn, MA, USA) and caspase-2 antibody (MAB3507) from Millipore (Billerica, MA, USA). Erlotinib was initially provided as gift from Genentech (San Francisco, CA, USA) and later acquired from LC Laboratories (Woburn, MA, USA). TAT-NBI1 was synthesized as described previously ${ }^{22}$ and it is also available from Calbiochem (Darmstadt, Germany); RC and etoposide were from Sigma (Munich, Germany) and necrostatin-1 from Enzo Life Sciences. The MDA-MB-468, SKBr3, MCF-7, A549, Jurkat, HL60 and Saos-2 cell lines were purchased from ATCC (Barcelona, Spain). Cell media (Leibovitz's I-15, 
DMEM, McCoys 5A, F12, RPMI) and fetal bovine serum was purchased for the different cell lines from GIBCO BRL Life Technologies (Paisley, UK).

Cell cultures. A549, MCF-7 and Saos-2 cell lines were grown in DMEM, the SKBr3 cell line was grown in McCoy's and the $\mathrm{HL}-60$ and Jurkat cell lines were grown in RPMI. All these media were supplemented with $10 \%$ fetal bovine serum and the cultures were maintained at $37^{\circ} \mathrm{C}$ under a $5 \% \mathrm{CO}_{2}$ atmosphere. The MDA-MB-468 and MDA-MB-231 cell lines were grown as a monolayer in Leibovitz's I-15 medium supplemented with $10 \%$ fetal bovine serum at $37^{\circ} \mathrm{C}$ without $\mathrm{CO}_{2}$.

MTT and trypan blue cell viability assays. Mitochondrial activity was measured using a MTT colorimetric assay. Cells were grown in 96-well plates at a cell density of 12500 cells/well for the MDA-MB-468 line and 5000 cells/well for the MCF-7 and SKBr3 cell lines. The HL60, Jurkat and Saos-2 cell lines were seeded at 3000,5000 and 10000 cells per well, respectively. The density for A549 was 2000 cells/well. After seeding, the cells were left to adhere to the plate overnight, they were then treated with the compounds of interest incubated at $37^{\circ} \mathrm{C}$. Four hours before the end of the treatment $20 \mu /$ well of MTT $(5 \mathrm{mg} / \mathrm{ml}$ in PBS) was added to each well and the plates were incubated for a further 4 hours at $37^{\circ} \mathrm{C}$. Finally, the medium was removed and the precipitated formazan crystals were dissolved in optical grade DMSO $(100 \mu \mathrm{l})$. The plates were read at $570 \mathrm{~nm}$ on a Wallac 1420 workstation, PerkinElmer Life Sciences (San Francisco, CA, USA). For IC50 determination, the cells were treated with seven different concentrations of the drugs and the cell viability determined by MTT. Data for three independent experiments were adjusted to variable slope sigmoidal dose-response curves, and the IC50 was determined using the Graph Pad 3.0 software. For trypan blue cell viability assays, cell suspensions were stained with trypan blue $0.004 \%$ (1:1), and cells were counted using an hemocytometer from Sigma. Cell death percentage was calculated from the ratio of positive-stained cells to total number of cells.

Determination of apoptosis by AnnexinV/PI staining. To estimate the number of apoptotic cells, cells were seeded as indicated above, and they were labeled with Alexa fluoresceinisothiocyanate-conjugated Annexin $\mathrm{V}$ (BD Bioscience, San Jose, CA, USA) together with PI dead cell counterstain, according to the manufacturer's recommendations.

Cell-cycle analysis. For cell-cycle analyses, MDA-MB-468 cells were seeded at 125000 cells/ml, MCF-7 and SKBr3 were seeded at $65000 \mathrm{cells} / \mathrm{ml}$ and A549 at $25000 \mathrm{cells} / \mathrm{ml}$. After treatments, the cells were fixed in $80 \%$ ice-cold ethanol and labeled with PI $(50 \mu \mathrm{g} / \mathrm{ml})$ in the presence of $500 \mu \mathrm{g} / \mathrm{ml}$ RNAase. Cytofluorometric determinations were performed with a Cytomics FC 500 from Beckman Coulter (Barcelona, Spain).

Immunofluorescence detection of clustered $\gamma-\mathrm{H} 2 \mathrm{AX}$ foci. MDAMB-468 cells were seeded on coverslips at a density of $125000 \mathrm{cells} / \mathrm{ml}$. After treatments, the cells were fixed in $4 \%$ formaldehyde/PBS for $15 \mathrm{~min}$, permeabilized with $0.3 \%$ Triton X-100/PBS for $15 \mathrm{~min}$ and blocked with $0.2 \%$ gelatin/PBS for $1 \mathrm{~h}$. After overnight incubation at $4{ }^{\circ} \mathrm{C}$ with the $\gamma-\mathrm{H} 2 \mathrm{Ax}$ primary antibody, the cells were labeled for $2 \mathrm{~h}$ with the Alexa Fluor $555 \mathrm{~F}(\mathrm{ab}) 2$ fragment goat anti-Rabbit secondary antibody at room temperature. Coverslips were mounted using Vectashield mounting medium with DAPI and foci were visualized on a Leica DM 6000 microscope (Leica DC500 camera) with a $\times 40$ objective (Weztlar, Germany).

Gene silencing with small interfering RNA. The siRNA for the human caspase-10 mRNA target sequence (No.6357) and the negative control siRNA (No.6568) were purchased from Cell Signaling. The siRNAs for caspase-2 and -8 (No.835:CASP-2 and No.841:CASP8, respectively) were purchased from Thermo Scientific (Walthman, MA, USA). The siRNA sequence for PIDD was provided by Dr. Tencho Tenev ${ }^{42}$ and purchased from Qiagen (Hilden, Germany). The siRNA oligonucleotides were transfected in Optimem at the recommended concentrations using Lipofectamine 2000 (Invitrogen, Paisley, UK), according to the manufacturer's instructions. At $48 \mathrm{~h}$ post-transfection, the cells were treated with the compounds of interest at the concentrations indicated.

Caspase activation assays in cellular models (caspase activity). To analyze caspase activation, MDA-MB-468 cells were seeded at 125000 cells/ $\mathrm{ml}$ and $\mathrm{A} 549$ at $50000 \mathrm{celll} / \mathrm{ml}$, and after $48 \mathrm{~h}$ in the presence of the compounds of interest at the concentrations indicated, caspase activity was measured as described previously in Mondragon et al. ${ }^{48}$

Cyt $c$ release from mitochondria. To quantify the release of Cyt $c$ from mitochondria, MDA-MB-468 cells were seeded at $125000 \mathrm{cell} / \mathrm{ml}$, and after $48 \mathrm{~h}$ in the presence of the compounds of interest at the concentrations indicated, the InnocyteTM Flow Cytometric Cytochrome c Release kit (Calbiochem) was used according to the manufacturer's recommendations. The cells were analyzed on a Cytomics FC 500 (Beckman Coulter) flow cytometer.

Immunoblotting. Whole-cell extracts were obtained by lysing cells in a buffer containing $25 \mathrm{mM}$ Tris- $\mathrm{HCl}$ pH 7.4, $1 \mathrm{mM}$ EDTA, $1 \mathrm{mM}$ EGTA, 1\% SDS plus protease and phosphatase inhibitors. The protein concentration was determined by the BCA protein assay. Cell lysates were resolved by SDS-PAGE, transferred to nitrocellulose membranes and immunoblotted following standard procedures.

Evaluation of erlotinib, RC and TAT-NBI1 sublethal concentrations. To determine such concentrations for the different cell lines, we defined as sublethal those concentrations that induced a percentage of cell death $<10 \%$ in MTT assays (Supplementary Table SII).

\section{Conflict of Interest}

The authors declare no conflict of interest.

Acknowledgements. We thank Genentech for initially providing erlotinib at the outset of the project. We thank Eliana Sirvent and Ana Giménez for technical assistance and Professor Oriol Bachs for critical reading of the manuscript. This work was supported by grants from the Spanish Ministry of Science and Innovation (MICINN-BIO2007-60066, -SAF2010-15512), and by Generalitat Valenciana (GV) Prometeo 2010/005 (funded in part with ERDF) to EP-P. TG is supported by a JAEpre fellowship from the Consejo Superior de Investigaciones Científicas (CSIC) and partially funded by Fondo Social Europeo, FSE.

1. Foley J, Nickerson NK, Nam S, Allen KT, Gilmore JL, Nephew KP et al. EGFR signaling in breast cancer: bad to the bone. Semin Cell Dev Biol 2010; 21: 951-960.

2. Klijn JG, Berns EM, Foekens JA. Prognostic factors and response to therapy in breast cancer. Cancer Surv 1993; 18: 165-198.

3. LeMaistre CF, Meneghetti C, Howes L, Osborne CK. Targeting the EGF receptor in breast cancer treatment. Breast Cancer Res Treat 1994; 32: 97-103.

4. Mendelsohn J, Baselga J. The EGF receptor family as targets for cancer therapy. Oncogene 2000; 19: 6550-6565.

5. Richard J, Sainsbury C, Farndon JR, Needham GK, Malcolm AJ, Harris AL. Epidermalgrowth-factor receptor status as predictor of early recurrence of and death from breast cancer. Lancet 1987; 329: 1398-1402.

6. Yarden $Y$. The EGFR family and its ligands in human cancer. signalling mechanisms and therapeutic opportunities. Eur J Cancer 2001; 37(Suppl 4): S3-S8.

7. Nicholson RI, Gee JM, Harper ME. EGFR and cancer prognosis. Eur J Cancer 2001; 37(Suppl 4): S9-S15.

8. Ettinger DS. Clinical implications of EGFR expression in the development and progression of solid tumors: focus on non-small cell lung cancer. Oncologist 2006; 11: 358-373.

9. Doebele RC, Oton AB, Peled N, Camidge DR, Bunn Jr PA. New strategies to overcome limitations of reversible EGFR tyrosine kinase inhibitor therapy in non-small cell lung cancer. Lung Cancer 2010; 69: 1-12.

10. Gridelli C, Bareschino MA, Schettino C, Rossi A, Maione P, Ciardiello F. Erlotinib in nonsmall cell lung cancer treatment: current status and future development. Oncologist 2007; 12: $840-849$

11. Matar P, Rojo F, Cassia R, Moreno-Bueno G, Di Cosimo S, Tabernero J et al. Combined epidermal growth factor receptor targeting with the tyrosine kinase inhibitor gefitinib (ZD1839) and the monoclonal antibody cetuximab (IMC-C225): superiority over singleagent receptor targeting. Clin Cancer Res 2004; 10: 6487-6501.

12. Steins M, Thomas M, Geissler M. Erlotinib. Recent Results Cancer Res 2010; 184: 21-31.

13. Dickler MN, Cobleigh MA, Miller KD, Klein PM, Winer EP. Efficacy and safety of erlotinib in patients with locally advanced or metastatic breast cancer. Breast Cancer Res Treat 2009; 115: $115-121$.

14. Cohen PR, Escudier SM, Kurzrock R. Cetuximab-associated elongation of the eyelashes: case report and review of eyelash trichomegaly secondary to epidermal growth factor receptor inhibitors. Am J Clin Dermatol 2011; 12: 63-67.

15. Ling YH, Li T, Yuan Z, Haigentz Jr M, Weber TK, Perez-Soler R. Erlotinib, an effective epidermal growth factor receptor tyrosine kinase inhibitor, induces P27KIP1 up-regulation and nuclear translocation in association with cell growth inhibition and G1/S phase arrest in human non-small-cell lung cancer cell lines. Mol Pharmacol 2007; 72: 248-258. 
16. Yu Z, Boggon TJ, Kobayashi S, Jin C, Ma PC, Dowlati A et al. Resistance to an irreversible epidermal growth factor receptor (EGFR) inhibitor in EGFR-mutant lung cancer reveals novel treatment strategies. Cancer Res 2007; 67: 10417-10427.

17. Rexer BN, Arteaga CL. Intrinsic and acquired resistance to HER2-targeted therapies in HER2 gene-amplified breast cancer: mechanisms and clinical implications. Crit Rev Oncog 2012; 17: 1-16.

18. Arteaga CL, Sliwkowski MX, Osborne CK, Perez EA, Puglisi F, Gianni L. Treatment of HER2-positive breast cancer: current status and future perspectives. Nat Rev Clin Oncol 2011; 9: 16-32.

19. Martinelli E, Troiani T, Morgillo F, Rodolico G, Vitagliano D, Morelli MP et al. Synergistic antitumor activity of sorafenib in combination with epidermal growth factor recepto inhibitors in colorectal and lung cancer cells. Clin Cancer Res 2010; 16: 4990-5001.

20. O'Donovan N, Byrne AT, O'Connor AE, McGee S, Gallagher WM, Crown J. Synergistic interaction between trastuzumab and EGFR/HER-2 tyrosine kinase inhibitors in HER-2 positive breast cancer cells. Invest New Drugs 2011; 29: 752-759.

21. Malumbres M, Barbacid M. Mammalian cyclin-dependent kinases. Trends Biochem Sci 2005; 30: 630-641.

22. Canela N, Orzaez M, Fucho R, Mateo F, Gutierrez R, Pineda-Lucena A et al. Identification of an hexapeptide that binds to a surface pocket in cyclin $A$ and inhibits the catalytic activity of the complex cyclin-dependent kinase 2-cyclin A. J Biol Chem 2006; 281 35942-35953.

23. Yamasaki F, Zhang D, Bartholomeusz C, Sudo T, Hortobagyi GN, Kurisu K et al. Sensitivity of breast cancer cells to erlotinib depends on cyclin-dependent kinase 2 activity. Mol Cancer Ther 2007; 6: 2168-2177.

24. Arteaga CL. Cdk inhibitor p27Kip1 and hormone dependence in breast cancer. Clin Cancer Res 2004; 10: 368S-371S

25. Wu FY, Wang SE, Sanders ME, Shin I, Rojo F, Baselga J et al. Reduction of cytosolic p27(Kip1) inhibits cancer cell motility, survival, and tumorigenicity. Cancer Res 2006; 66: 2162-2172.

26. Fleming IN, Hogben M, Frame S, McClue SJ, Green SR. Synergistic inhibition of ErbB signaling by combined treatment with seliciclib and ErbB-targeting agents. Clin Cancer Res 2008; 14: 4326-4335.

27. Hidalgo M, Siu LL, Nemunaitis J, Rizzo J, Hammond LA, Takimoto $C$ et al. Phase I and pharmacologic study of OSI-774, an epidermal growth factor receptor tyrosine kinase inhibitor, in patients with advanced solid malignancies. J Clin Oncol 2001; 19: 3267-3279.

28. van Engeland M, Nieland LJ, Ramaekers FC, Schutte B, Reutelingsperger CP. Annexin $V$-affinity assay: a review on an apoptosis detection system based on phosphatidylserine exposure. Cytometry 1998; 31: 1-9.

29. Janicke RU. MCF-7 breast carcinoma cells do not express caspase-3. Breast Cancer Res Treat 2009; 117: 219-221.

30. Petrini JH, Stracker TH. The cellular response to DNA double-strand breaks: defining the sensors and mediators. Trends Cell Biol 2003; 13: 458-462.

31. Muller-Tidow C, Ji P, Diederichs S, Potratz J, Baumer N, Kohler G et al. The cyclin A1-CDK2 complex regulates DNA double-strand break repair. Mol Cell Biol 2004; 24 8917-8928.

32. Rogakou EP, Pilch DR, Orr AH, Ivanova VS, Bonner WM. DNA double-stranded breaks induce histone H2AX phosphorylation on serine 139. J Biol Chem 1998: 273: 5858-5868.
33. Yuan J, Adamski R, Chen J. Focus on histone variant $\mathrm{H} 2 \mathrm{AX}$ : to be or not to be. FEBS Lett 2010; 584: 3717-3724.

34. Capasso H, Palermo C, Wan S, Rao H, John UP, O'Connell MJ et al. Phosphorylation activates Chk1 and is required for checkpoint-mediated cell cycle arrest. J Cell Sci 2002; 115(Pt 23): 4555-4564

35. Danial NN. BCL-2 family proteins: critical checkpoints of apoptotic cell death. Clin Cancer Res 2007; 13: 7254-7263

36. Danial NN, Korsmeyer SJ. Cell death: critical control points. Cell 2004; 116: 205-219.

37. Lindsay J, Esposti MD, Gilmore AP. Bcl-2 proteins and mitochondria-specificity in membrane targeting for death. Biochim Biophys Acta 2011; 1813: 532-539.

38. Gyrd-Hansen M, Meier P. IAPs: from caspase inhibitors to modulators of NF-kappaB, inflammation and cancer. Nat Rev Cancer 2010; 10: 561-574.

39. Petersen SL, Wang L, Yalcin-Chin A, Li L, Peyton M, Minna J et al. Autocrine TNFalpha signaling renders human cancer cells susceptible to Smac-mimetic-induced apoptosis. Cancer Cell 2007; 12: 445-456.

40. Wang L, Du F, Wang X. TNF-alpha induces two distinct caspase-8 activation pathways. Cell 2008; 133: 693-703.

41. Feoktistova M, Geserick P, Kellert B, Dimitrova DP, Langlais C, Hupe M et al. clAPs block ripoptosome formation, a RIP1/caspase-8 containing intracellular cell death complex differentially regulated by cFLIP isoforms. Mol Cell 2011; 43: 449-463.

42. Tenev T, Bianchi K, Darding M, Broemer M, Langlais C, Wallberg F et al. The ripoptosome, a signaling platform that assembles in response to genotoxic stress and loss of IAPs. Mol Cell 2011; 43: 432-448.

43. Costa DB, Halmos B, Kumar A, Schumer ST, Huberman MS, Boggon TJ et al. BIM mediates EGFR tyrosine kinase inhibitor-induced apoptosis in lung cancers with oncogenic EGFR mutations. PLoS Med 2007; 4: 1669-1679.

44. Janssens S, Tinel A. The PIDDosome, DNA-damage-induced apoptosis and beyond. Cell Death Differ 2012; 19: 13-20.

45. Bach S, Knockaert M, Reinhardt J, Lozach O, Schmitt S, Baratte B et al. Roscovitine targets, protein kinases and pyridoxal kinase. J Biol Chem 2005; 280: 31208-31219.

46. Hitomi J, Christofferson DE, Ng A, Yao J, Degterev A, Xavier RJ et al. Identification of a molecular signaling network that regulates a cellular necrotic cell death pathway. Cell 2008; 135: 1311-1323.

47. Lee MJ, Ye AS, Gardino AK, Heijink AM, Sorger PK, Macbeath G et al. Sequential application of anticancer drugs enhances cell death by rewiring apoptotic signaling networks. Cell 2012; 149: 780-794.

48. Mondragon L, Orzaez M, Sanclimens G, Moure A, Arminan A, Sepulveda P et al. Modulation of cellular apoptosis with apoptotic protease-activating factor 1 (apaf-1) inhibitors. J Med Chem 2008; 51: 521-529.

Cell Death and Disease is an open-access journal published by Nature Publishing Group. This work is licensed under the Creative Commons Attribution-NonCommercial-No Derivative Works 3.0 Unported License. To view a copy of this license, visit http://creativecommons.org/licenses/by-nc-nd/3.0/

\section{Supplementary Information accompanies the paper on Cell Death and Disease website (http://www.nature.com/cddis)}

